\title{
AN EVALUATION OF THREE NEW BLOOD-GAS \\ ANALYZER SYSTEMS
}

\author{
B. VINET ${ }^{\circ}$
}

FOH TWO YEARs we have been involved in the introduction of a new generation of blood gas analyzers. The characteristic features of this new kind of apparatus is the use of a digital display to present the results of the analyses and also of derived parameters such as bicarbonate, total carbon dioxide and base excess, calculated by means of a mini-computer. The previous generation of analyzers was represented by the BMS-2, BMS-3 of Radiometer and the IL 113 and 313 of Instrumentation Laboratories International Canada.

In order to establish if the new class of analyzers represents progress in bloodgas analysis and how they compare with each other we have studied the performances of three analyzers of this new generation, namely the ABL-1 of Radiometer, the Corning 165 from Corning Scientific Instruments and the IL 513 of Instrumentation Laboratories. These instruments were kindly loaned to us by the manufacturers for periods varying from two to five days. The analyzers were judged for their accuracy, precision, automation and speed of analysis.

\section{Material and Methods}

In order to evaluate the accuracy of the apparatus, we used the same blood sample seven times to measure $\mathrm{pH}, \mathrm{P}_{\mathrm{O}_{2},}, \mathrm{P}_{\mathrm{CO}_{2}}$, bicarbonate, total $\mathrm{CO}_{2:}$ and base excess. Calibration values were checked between each determination and care was taken to avoid air contamination of the sample. Each analyzer was used as described in the operations manual and under the supervision of a representative of the respective company. One exception was with the IL 513 where the sampling process was modified. According to the operations manual blood is aspirated automatically by inserting a metallic tube inside the open blood syringe. However, during the sampling process, air bubbles may be introduced into the syringe, producing air contamination of the sample which interferes with subsequent determinations. To avoid this we have used a short length of Tygon tubing which was interposed to provide an air-tight connection of the sampling needle with the syringe. The blood was introduced into the electrode chambers by pressure on the plunger of the syringe and by manual operation of the sampling pump.

All analyses were carried out for normal values $\left(\mathrm{pH} 7.40, \mathrm{P}_{\mathrm{O}_{2}} 80 \mathrm{~mm} \mathrm{Hg}, \mathrm{P}_{\mathrm{co}}\right.$ $40 \mathrm{~mm} \mathrm{Hg}$ ) for high values ( $\mathrm{pH} 7.6, \mathrm{P}_{\mathrm{O}_{2}} 300 \mathrm{~mm} \mathrm{Hg}, \mathrm{P}_{\mathrm{CO}_{2}} 100 \mathrm{~mm} \mathrm{Hg}$ ) and for low values ( $\mathrm{pH}$ of $7.0, \mathrm{PO}_{2} 40 \mathrm{~mm} \mathrm{Hg}, \mathrm{P}_{\mathrm{CO}_{2}} 10 \mathrm{~mm} \mathrm{Hg}$ ). Mean values and standard deviations were calculated.

'Service de Biochimie, Hôpital Notre-Dame, (C.P. 1560) 1560 est, rue Sherbrooke, Montréal, P. Québec, Canada. 
Accuracy was checked by the analysis of a normal Versatol ${ }^{\circ}$ for the $\mathrm{pH}$ and $\mathrm{P}_{\mathrm{CO}_{2}}$. If the measured values were within the standard deviation for the Versatol $\left( \pm 0.01 \mathrm{pH}\right.$ unit, $\pm 2 \mathrm{~mm} \mathrm{Hg}$ for the $\left.\mathrm{P}_{\mathrm{CO}_{2}}\right)$ the results are considered accurate. $\mathrm{Po}_{2}$ accuracy was checked against tonometered blood using the normal sampling process of the analyzers.

\section{RESULTS}

As mentioned earlier, all three instruments have in common that they present the results on a digital display and that they incorporate a calculator. They all give values for $\mathrm{pH}, \mathrm{P}_{\mathrm{O}_{2}}, \mathrm{P}_{\mathrm{CO}_{2}}$, bicarbonate, total $\mathrm{CO}_{2}$, base excess. The ABL-1 in addition also measures the haemoglobin concentration and calculates percent of oxygen saturation; the standard base excess is corrected for the haemoglobin concentration. The value for haemoglobin concentration must be given to the two other analyzers in order to have base excess corrected by their computers.

The new blood-gas analyzers use the same principle of measurements as their predecessors, namely specific electrodes. The temperature of the electrodes is kept constant at $37^{\circ} \mathrm{C}$ and this is achieved in one of three different ways. With the ABL-1, the electrodes are placed inside a plastic chamber through which thermostatically controlled air is recirculated. The temperature of the electrodes in the Corning model is kept constant by their placement inside a metallic block instead of a water jacket. Temperature fluctuations of the electrodes were not measured. It was assumed that if large fluctuations did exist these would be reflected by a large standard deviation; but this was not the case.

One of the distinctive features of the ABL-1 is its calibration process: buffers of secret composition are equilibrated with gas mixtures and circulated inside the electrodes. These gas mixtures are made automatically within the apparatus by mixing room air with carbon dioxide. The composition of these gas mixtures is a characteristic of the instrument and cannot be changed easily. The ABL-1 computer converts this composition of the mixture into $\mathrm{P}_{\mathrm{O}_{2}}$ and $\mathrm{P}_{\mathrm{CO}}$, for changes in barometric pressure which the instrument itself monitors. The oxygen concentration of the room air is assumed to be constant. This introduces a small error since we have determined in our laboratory that the percentage of oxygen in the air varies between 20.8 per cent to 21.0 per cent as measured with a Scholander's apparatus.

A nomogram constructed by Radiometer was used to confirm the accuracy of the instrument. The difference between the two calibration values for $\mathrm{pH}, \mathrm{P}_{\mathrm{O}_{2}}$ and $\mathrm{P}_{\mathrm{CO}: 2}$ must lie within limits set by the nomogram for a given barometric pressure. If calibration values are shown to be unsatisfactory, correction is effected by changing the electrodes or by adjustment of the electronic circuit of the computer.

\footnotetext{
-The Versatols are freeze-dried sera with known values for the $\mathrm{pH}, \mathrm{P}_{\mathrm{CO}_{2}}$ and total $\mathrm{CO}_{2}$. They are sold by the Warner Chilcott Laboratories, Diagnostic Reagents Division, 727 King Street West, Toronto, Ontario.

Just before the analysis, a buffer is added to the powder and after gentle mixing we obtain a reconstituted serum. There are three kinds of Versatol: the normal Versatol; with values for $\mathrm{pH}, \mathrm{P}_{\mathrm{CO}}$ and total $\mathrm{CO}_{2}$ corresponding to those of a normal serum; the acidosis Versatol with values corresponding to those of the acidosis state and the alkalosis-Versatol corresponding to those of the alkalosis state.
} 


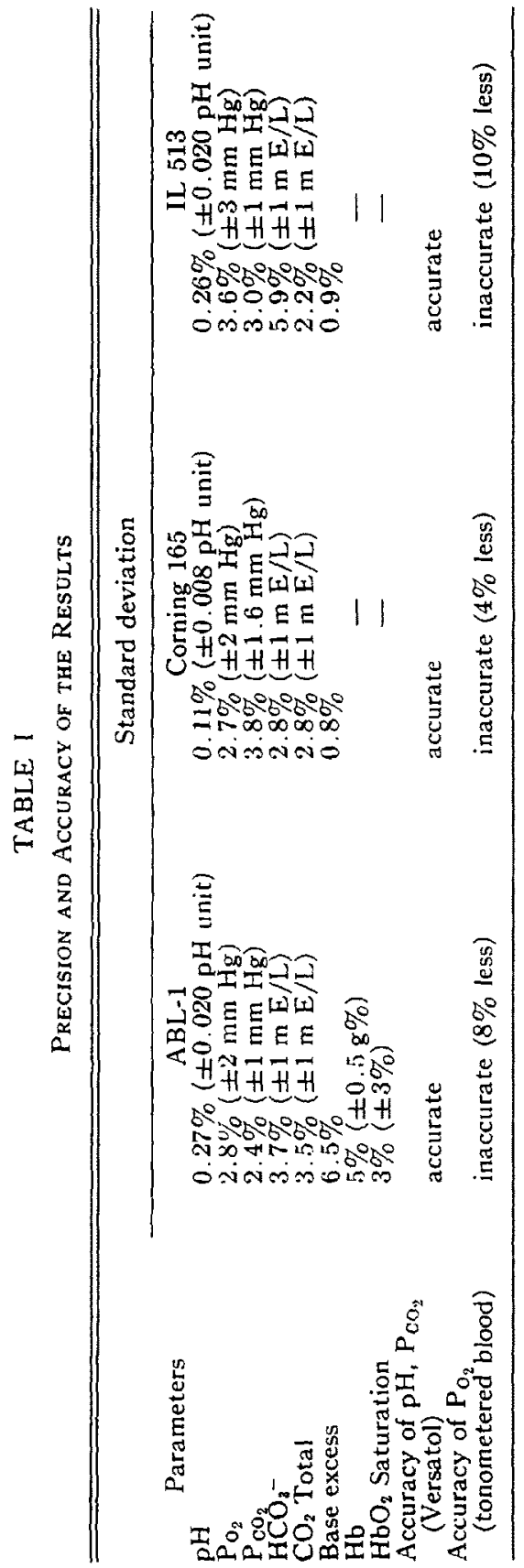


The other two analyzers use a less sophisticated and also less rigid calibration system. They establish two points of calibration with buffers of known $\mathrm{pH}$, and with two gases of known oxygen and carbon dioxide composition. The calibration values obtained are used to adjust the analyzers manually. The calibration gases must be humidified before entering the $\mathrm{P}_{\mathrm{O}_{2}}$ and the $\mathrm{P}_{\mathrm{CO}_{2}}$ electrodes. In the Corning 165 the humidifying water is at $37^{\circ} \mathrm{C}$ while in the $\mathrm{Il} 513$ it is at room temperature. This fact is not indicated in the IL operating manual but it must be kept in mind when calculating calibration values.

As far as temperature control is concerned the sampling devices also differ for the three analyzers. In order to introduce blood inside the ABL-1 it is necessary to press the syringe against a flexible cork pierced in the middle by a metallic needle. The blood can be injected or aspirated. A light indicates when sufficient blood has entered the electrodes. If the temperature of the electrodes is incorrect or if the analyzer is set on calibration, it is impossible to introduce the sample. The Corning has a conventional sampling system: a luerlock type syringe is connected to the apparatus adaptor. The blood is inserted and observation through a prism system determines whether enough blood or air bubbles have entered the electrodes. Blood can be aspirated by activating a peristaltic pump.

The IL 513 uses a more complicated device: a metallic tube of a few mm external diameter is inserted into the syringe and blood is aspirated by pressing a button. The route followed by the blood can be easily followed and it is possible to see if air bubbles are entrapped within the electrodes. When the sampling light stops flashing enough blood is inside the apparatus. It is possible to introduce the sample manually and without air contamination in the manner described above.

The ABL-1 is the most automated system of the three: to carry out an analysis, the only manipulation required is the injection of blood. The computer will calculate and print the results and will initiate automatically the washing cycle and calibration. All these processes are completed in about 120 seconds. The IL 513 is also well automated: after pressing the sampling button, values are available to be read and derived parameters are calculated. The washing cycle is started automatically after the results have been read. The calibration process must be initiated by pressing the appropriate button. An analysis requires about 72 seconds. The Corning 165 is the least automated, and indeed it might be described as only semiautomatic. Each operation (introduction of calibration buffers and gases, of the sample, washing and calibration) must be controlled manually. It is the slowest of the three instruments to complete an analysis ( 240 seconds). This is due largely to the instability of the electrodes which take a long time to reach equilibrium.

The maintenance schedule for the three analyzers is quite similar and involves emptying the waste bottles, adding fresh buffers, changing electrode membranes, checking the quantity in the gas cylinders. The electrodes are well located in all three and replacement of the membranes does not present any special problem.

Table I presents the relative standard deviation obtained for the various parameters with the three blood gas analyzers. Absolute variation calculated from the relative standard deviations with normal values are given in brackets.

The Corning 165 is the most accurate instrument as far as measurement of $\mathrm{pH}$ is concerned. For the other parameters deviations are about the same with the three analyzers. 
TABLE II

General Characteristics

\begin{tabular}{|c|c|c|c|}
\hline Characteristics & ABL-1 & Corning 165 & IL 513 \\
\hline \multirow{7}{*}{$\begin{array}{l}\text { Price (Dollars) } \\
\text { Dimensions in } \mathrm{cm} \text {. } \\
\text { (width, depth, height) } \\
\text { Recording of results } \\
\text { Calibration } \\
\text { Sampling } \\
\text { Minimum blood volume } \\
\text { Time between two } \\
\text { analyses }\end{array}$} & $\$ 15,000$ & $\$ 6,950$ & $\$ 9,950$ \\
\hline & $73 \times 35 \times 37$ & $41 \times 34 \times 15$ & $62 \times 42 \times 33$ \\
\hline & standard & none & optional \\
\hline & liquid & gas & \\
\hline & manual-automatic & manual & automatic \\
\hline & $.500 \mu 1$ & $125 \mu \mathrm{l}$ & $250 \mu \mathrm{l}$ \\
\hline & 120 seconds & 240 seconds & 72 seconds \\
\hline
\end{tabular}

The three blood gas analyzers give exact values when compared to a Versatol. It is not recommended by Radiometer to check the accuracy of the ABL-I by this procedure because the electrodes are saturated with gaseous $\mathrm{CO}_{2}$ when not in use. Bearing in mind this remark we have checked the ABL-1 with a Versatol and found exact determinations. But if we measure the $\mathrm{pH}$ of a phosphate buffer we have an inexact value probably due to a $\mathrm{CO}_{2}$ contamination of the sample.

The $\mathrm{P}_{\mathrm{O}_{2}}$ electrodes were found to be inexact except with the ABL-1. This probably reflects the blood gas factor which is known to be a factor when calibrating with gas mixtures ${ }^{1}$ as is the case for the IL 513 and the Corning 165. But it is possible to adjust manually the calibration values of these two analyzers and by doing so accurate values for the $P_{O_{2}}$ are obtained.

We have also checked the effectiveness of the wash system of the three instruments: a blood sample is analyzed, the values are retained and a blood sample with an abnormal high value or abnormal low value is analyzed. After the wash and calibration cycles, the first sample is analyzed a second time. With the three instruments we have found values corresponding to the first ones within the standard deviation. This indicates that two consecutive samples, with extreme values, are not affected by one another. Table II gives the general characteristics of each analyzer.

\section{Discussion}

Overall, this new generation of blood gas analyzers represents considerable progress. Accuracy is greatly improved for all parameters. The variations are now of the order of $0.02 \mathrm{pH}$ unit, $2-5 \mathrm{~mm} \mathrm{Hg}$ for $\mathrm{P}_{\mathrm{O}_{2 .}}$ and $1-4 \mathrm{~mm} \mathrm{Hg}$ for $\mathrm{P}_{\mathrm{CO}_{2}}$ instead of $0.05-0.10 \mathrm{pH}$ unit, 7-17 mm Hg for $\mathrm{P}_{\mathrm{O}_{2} .2}$ and $2-6 \mathrm{~mm} \mathrm{Hg}$ for $\mathrm{P}_{\mathrm{CO}_{2}}$ for the previous series of instruments. ${ }^{2}$ This is probably accomplished by better design of the electrodes and temperature control systems: unfortunately the calibration with gases still results in lower $\mathrm{P}_{\mathrm{O}_{2}}$ results, ${ }^{1,3}$

The greatest progress is represented by automation and by increased speed of analysis. The only manipulation required is the introduction of the blood sample and pressing of the appropriate buttons to initiate the desired operations. The incorporation of calculators to derive the values for bicarbonate, total carbon dioxide and base excess avoid the use of a nomogram, which greatly facilitates the task of blood gas analysis. The presentation of the results on a digital display and their possible printout eliminates the potential mistake inherent in the readout of a graduated scale. 
The minimum volume of blood necessary for analysis has also been reduced to the order of 125 to $500 \mu \mathrm{l}$ which makes these analyzers perfectly suitable for blood gas analysis on a micro scale.

Of the three apparati investigated the ABL-1 is surely the most advanced: it calculates more parameters (haemoglobin, oxyhaemoglobin saturation, and barometric pressure) and operations are fully automated and fully controlled by the computer. However, it is a rigid apparatus making it impossible to correct calibration.

The Corning 165 is between the previous generation of blood gas analyzers and the present one. Because of the accuracy of its results, the incorporation of a computer and its digital readout system, it is of the new generation. But its operations are not under computer control and it takes a long time to stabilize.

The IL 513 is halfway between the Corning 165 and the ABL-1. Its results are accurate, it is possible to correct its calibration and it is the fastest blood gas analyzer.

\section{SUMMARY}

Three new pH-blood-gas analyzer systems have been evaluated. These are the ABL-1, the Corning 165, the Il 513. Because of automation of analysis, accuracy, and speed of analysis, this generation of instruments represents great progress over the previous one.

The ABL-1 is the most automated system: all analyses are computer controlled. The $\mathrm{pH}, \mathrm{P}_{\mathrm{O}_{2}}$ and $\mathrm{P}_{\mathrm{CO}_{2}}$ values are accurate. Calibration can not be adjusted.

The Corning 165 is the least automated system. Its $\mathrm{pH}$ determinations are the most accurate and it is the one which uses the smallest volume of blood (125 $\mu \mathrm{l})$. However it is the least stable and takes the longest time for completion of the analysis.

The IL 513 is probably the best balanced system and its calibration can be modified. Its operation is well automated and its results are accurate.

\section{RÉSUMÉ}

Nous avons évalué trois nouveaux systèmes pour la mesure du $\mathrm{pH}$ des gaz sanguins. Suivant leur automation, la vitesse d'analyse, leur précision, cette génération représente d'immenses progrès sur les anciens modèles d'analyseurs sanguins.

L'ABL-1 est l'appareil le plus automatisé: toutes les opérations y sont contrôlées par un ordinateur. Le $\mathrm{pH}$, la $\mathrm{P}_{\mathrm{OO}_{2}}$ et la $\mathrm{P}_{\mathrm{O}_{2}}$ y sont précis et exacts. Sa calibration ne peut être modifiée.

Le Corning 165 est le système le moins automatique. Ses valeurs de $\mathrm{pH}$ sont les plus précises et il est celui qui nécessite le plus petit volume de sang. C'est aussi celui qui est le moins stable et celui qui requiert le plus de temps pour une analyse.

Le IL 513 est probablement le système le mieux équilibré. Sa calibration est maléable, ses opérations sont automatiques et ses résultats sont précis. 


\section{ACKNOWLEDGMENTS}

I want to thank the Radiometer Company (Canlab), the Corning Scientific Instruments (Fisher) and IL International Canada Co. (Canlab) for loaning their apparatus and I want to thank their salesmen for their helpful collaboration.

\section{REFERENCES}

1. Adam, A.P. \& Morgan-Hughes, J.O. Determination of the blood-gas factor of the oxygen electrode using a new tonometer, Brit. J. Anaesth. 39: 107 (1967).

2. Hill, D.W. \& Tilsley, C. A comparative study of the performance of five commercial blood gas pH electrode analyzers. Brit. J. Anaesth. 45: 647 (1973).

3. Hulands, G.H., Nunn, J.F., \& Paterson, G.M. Calibration of polarographic electrodes with glycerol-water mixtures. Brit. J. Anaesth. 42: 9 (1970). 